\title{
First report of odontoglossum ringspot virus from Cymbidium goeringii (Orchidaceae) in Jiangsu Province, China
}

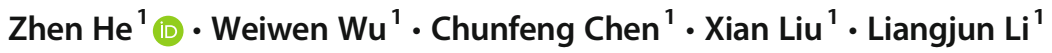

Received: 12 March 2018 / Accepted: 5 June 2018 / Published online: 19 June 2018

(C) Società Italiana di Patologia Vegetale (S.I.Pa.V.) 2018

Cymbidium goeringii is the type specimen of the species reported from Japan, and presently widely distributed in east Asia (Yao et al. 2007). Viral diseases are one of important restrictive factors for plants of the family Orchidaceae in the world, particulary those caused by odontoglossum ringspot virus (ORSV) and cymbidium mosaic virus (CymMV). Previously, both ORSV and CymMV were isolated from Phalaenopsis and Oncidium orchids in China (Liu et al. 2013), however, there are few reports on $C$. goeringii. During the spring to summer of 2017, virus-like symptoms such as yellowing, mottling, and mosaic were observed on $C$. goeringii in several commercial plantations in Jiangsu province. To identify the viruses, twenty-five samples with clear symptoms were collected in Jiangsu province. The viral RNA was extracted by TaKaRa MiniBEST Plant RNA Extraction

Electronic supplementary material The online version of this article (https://doi.org/10.1007/s42161-018-0097-8) contains supplementary material, which is available to authorized users.

Liangjun Li

1jli@yzu.edu.cn

Zhen $\mathrm{He}$

hezheng225@163.com; hezhen@yzu.edu.cn

Weiwen $\mathrm{Wu}$

www794191245@163.com

Chunfeng Chen

15705275218@163.com

Xian Liu

18252715593@163.com

1 School of Horticulture and Plant Protection, Yangzhou University, Wenhui East Road No.48, Yangzhou 225009, Jiangsu Province, People's Republic of China
Kit (TaKaRa). One step RT-PCR was performed using a kit (Tiangen) according to the manufacturer's instructions, and the primers reported by Rao et al. (2015), which amplified a 500 and 600 bp long region of the $\mathrm{CP}$ gene of the two viruses, respectively. ORSV was detected in twenty-four (96\%) $C$. goeringii samples by RT-PCR. However, CymMV was not detected by RT-PCR in these samples, possibly because of the limited samples. These results were confirmed by DASELISA (Qiaodu). The purified amplicons were cloned and sequenced. Four sequences were determined and submitted to GenBank (MG773324-MG773327). BLASTN analysis showed that these sequences shared $99 \%$ nucleotide identity with a ORSV isolate (AF033848). To our knowledge, this is the first report of ORSV in C. goeringii in Jiangsu, China.

Acknowledgements This work was supported by grants from the National Natural Science Foundation of China (No. 31601604), the Natural Science Foundation of the Jiangsu Higher Education Institutions of China (No. 16KJB210015), China Agriculture Research System (CARS-24) and independent innovation of agricultural sciences in Jiangsu province (No.CX(16)1011).

\section{References}

Liu FX, Han YC, Li WD, Shi XQ, Xu W, Lin MG (2013) Incidence of Cymbidium mosaic virus and Odontoglossum ringspot virus affecting Oncidium orchids in Hainan Island, China. Crop Prot 54: 176-180

Rao X, Li Y, Sun J, Li X, Li MH, Xiang MM (2015) Genetic diversities of cymbidium mosaic virus and odontoglossum ringspot virus isolates based on the coat protein genes from orchids in Guangdong province, China. J Phytopathol 163:324-329

Yao X, Gao L, Yang B (2007) Genetic diversity of wild Cymbidium goeringii (Orchidaceae) populations from Hubei based on intersimple sequence repeats analysis. Front Biol China 2:419-424 